Petar Filipović $₫$

Damir Dović

Ivan Horvat

Borjan Ranilović

https://doi.org/10.21278/TOF.45Si1009821

ISSN 1333-1124

eISSN 1849-1391

\title{
NUMERICAL INVESTIGATION OF COVER PLATE CONFIGURATIONS EFFECT ON THERMAL CHARACTERISTICS OF A POLYMER SOLAR COLLECTOR
}

\begin{abstract}
Summary
This paper presents numerical analysis on influence of different configurations on thermal performances of a polymer solar collector. In the first step two configurations including single cover plate and honeycomb cover plate are investigated. Results showed that collector with single cover plate is more efficient than collector with honeycomb cover plate at lower reduced temperature values. Honeycomb cover plate behaves like insulator, increasing overall collector top resistance to heat loss which results in higher thermal efficiency at higher reduced temperature values. This also leads to higher temperatures at stagnation regimes. Also, in this paper two passive overheating protection based on natural convection are examined. Channels inside honeycomb cover plate can be connected to channels inside absorber plate allowing for air to flow inside collector. Three different channel widths are considered 4.25, 10, and $20 \mathrm{~mm}$. With such passive method, it is possible to reduce average absorber temperature up to $\sim 20^{\circ} \mathrm{C}$. Second overheating protection uses additional channel below the absorber plate allowing the flow of ambient air. With this method it is possible to reduce temperatures up to $\sim 50^{\circ} \mathrm{C}$ but it also causes high temperature gradient, $50^{\circ} \mathrm{C} / \mathrm{m}$ of collector length which can potentially result in deformation of polymer solar collector. Present work is a part of the research focused at development of a low-cost polymer solar collector that operates in a drain back system.
\end{abstract}

Key words: $\quad$ numerical simulation, FLUENT, heat transfer, polymer solar collector, overheating protection

\section{Introduction}

Further utilization of solar thermal energy is limited due to relatively high manufacturing costs of conventional flat plate solar thermal collectors (FPC). Consequently, development of solar technology is more and more oriented towards the use of polymeric materials. On the market, different polymeric materials exist, from low-cost commodity to high-cost engineering polymer. All polymeric materials have poor thermal, optical and mechanical properties compared to materials traditionally used in the FPC production 
(cooper, glass, etc.). Therefore, a major challenge that needs to be solved is how to prevent degradation and deformation of the polymeric materials that occurs even at relatively low temperatures while maintaining low production cost at the same time. Polymeric materials are already used in production of solar collectors, such as ones used for pool water heating or in some cases when only individual parts within solar thermal system are made. Use of polymeric materials in solar technology is reviewed in [1] and [2]. It is shown that use of polymeric materials can reduce the collector weight by $50 \%$ and have other advantages such as reduced cost of materials and manufacture, resistance to corrosion and mineral build-up, etc. As mentioned before, solving degradation of material is a major issue in production of polymer solar thermal collectors. Thus, information about aging behaviour and temperature loads are important factors in the design process of a polymer solar collector. Experimental investigation of aging behaviour of various commodity and engineering plastics is done in papers $[3,4]$. Materials were tested at a normal operating regime (exposed to water with temperature of $80^{\circ} \mathrm{C}$ ) and stagnation regime (exposed to hot air with temperature of $140^{\circ} \mathrm{C}$ ). Degradation is reported on all tested materials and it is suggested that such collectors should be used in northern climates and should have some kind of overheating protection. There are also some other experimentally based researches that deal with degradation of material, but such tests, as performed in [5], are time and financially consuming. Hence, numerical approach is more suitable for finding an appropriate solution before final testing. Numerical simulations are widely used to assess thermal performances of conventional flat plate collectors. Different concepts of flat plate collectors can also be studied using numerical simulations [6-8]. Since the proposed polymer solar collector is basically flat plate type, same heat transfer phenomena occur as in conventional flat plate collectors. This enables to use findings from work done on conventional flat plate collectors and apply it to the analyses of the polymer solar collector. Numerical analysis of different polymer solar collector design with FLUENT software is shown in papers [9-11]. In these papers, only thermal efficiency is evaluated.

An overview of strategies for control of high temperatures in conventional collectors is shown in [12]. Experimental and numerical analysis of passive overheating protection for flat plate solar collector is presented in [13]. This mechanism included external air flowing in the gap between absorber and cover plate. External air flow can bring dust and dirt inside collector consequently reducing the efficiency in normal operating regime. Authors stated that such protection can reduce maximum temperature from $170^{\circ} \mathrm{C}$ to $120^{\circ} \mathrm{C}$. Presented active method is not preferable since it would increase cost of the collector. Thus, passive cooling methods are more interesting for application in the manufacturing process of a polymer solar collector. Water passive cooling method based on thermosyphon effect applied to reduce the temperature of PV modules is described in [14]. Different water cooling systems in PV systems are investigated with the use of computational fluid dynamics methods in [15]. Since the main purpose of applied methods in mentioned papers is to reduce temperature of PV module, similar methods can be applied to cool down the polymer solar collector. Passive method based on prismatic structures is shown in [16]. Authors reported that temperatures in the collector can be reduced up to $60^{\circ} \mathrm{C}$ when collector is exposed to $300 \mathrm{~W} / \mathrm{m}^{2}$ light source. With thermotropic overheating protection it is possible to reduce absorber temperature up to $29 \mathrm{~K}$ in façade-integrated solar thermal collectors [17]. One-dimensional heat transfer model of a polymer solar flat plate collector with a thermotropic material is developed in [18]. Results proved that thermotropic material can be successfully applied to provide overheating protection.

Literature review shows that there is some work done on assessing thermal efficiency of a polymer solar collector using numerical analysis. On the other hand, there is a little work done concerning the evaluation of thermal loads and obtained material temperatures at various 
regimes in polymer solar collectors using numerical methods. In the reviewed literature only thermotropic based protection in polymeric solar collectors is investigated.

In this paper, the passive cooling methods applied to reduce temperature in polymer solar collectors are described and investigated along with the thermal efficiency assessment of the proposed collector design.

\section{Numerical modelling}

\subsection{Heat transfer inside solar collector}

Heat transfer inside solar collector is complex phenomena that include all three heat transfer mechanisms: conduction, convection, and radiation. Free convection occurs in the enclosure between absorber and cover plates. Free convection problem inside polymer solar collectors is done by solving continuity equation Eq. (1), momentum equation Eq. (2), and energy equation Eq. (3).

$$
\begin{gathered}
\frac{\partial\left(\rho u_{j}\right)}{\partial x_{j}}=0 \\
\frac{\partial\left(\rho u_{i} u_{j}\right)}{\partial x_{j}}=-\frac{\partial p}{\partial x_{i}}+\mu \frac{\partial}{\partial x_{j}}\left(\frac{\partial u_{j}}{\partial x_{i}}+\frac{\partial u_{i}}{\partial x_{j}}\right) \\
+\frac{\partial}{\partial x_{j}}\left[\left(\mu_{v}-\frac{2}{3} \mu\right) \frac{\partial u_{k}}{\partial x_{k}} \delta_{j i}\right]+\rho f_{i} \\
\frac{\partial\left(\rho c u_{j} T\right)}{\partial x_{j}}=\frac{\partial}{\partial x_{j}}\left(\lambda \frac{\partial T}{\partial x_{j}}\right)
\end{gathered}
$$

Density temperature dependence is taken into account by Boussinesq's assumption according to Eq. (4). Thermal expansion coefficient of the fluid is determined as a reciprocal value of the average fluid temperature (in this case air) inside an enclosure in which free convection is observed. It is important to note that such assumption is valid only for laminar flow and relatively small temperature difference between fluid and surface Eq. (5).

$$
\begin{gathered}
\rho \cong \rho_{\infty}\left[1-\beta^{\prime}\left(T-T_{\infty}\right)\right] \\
\beta^{\prime}\left(T-T_{\infty}\right) \ll 1
\end{gathered}
$$

Radiative heat transfer due to longwave or infrared radiation is considered by Discrete ordinates (DO) radiation sub-model available within FLUENT program package. This model solves radiative transport equation Eq. (6), for a finite number of directions $\vec{\Omega}$, each associated with vector $\overrightarrow{\mathrm{s}}$ fixed in the global Cartesian $\operatorname{system}(\mathrm{x}, \mathrm{y}, \mathrm{z})$.

$$
\begin{gathered}
\left.d \Omega \frac{d I(\vec{r}, \vec{\Omega})}{d \Omega}\right|_{\vec{\Omega}} \\
=-\left(a+\sigma_{s}\right) I(\vec{r}, \vec{\Omega})+a n^{2} \frac{\sigma T^{4}}{\pi} \\
+\frac{\sigma_{s}}{4 \pi} \int_{\vec{\Omega}=4 \pi} I\left(\vec{r}, \vec{\Omega}^{\prime}\right) \phi\left(\vec{r}, \vec{\Omega}^{\prime} \rightarrow \vec{\Omega}\right) d \Omega^{\prime}
\end{gathered}
$$


Left-hand side of Eq. (6) represents change of radiation intensity. On the right-hand side of the equation, first term corresponds to absorption and scattering losses, second term represents absorption of emitted radiation by molecules of the different involved media (air, cover plate, absorber plate) at temperature $\mathrm{T}$, and last term accounts for losses due to incoming scattered radiation. Such approach in assessing polymer collector thermal performances is validated by authors in [19]

\subsection{Description of proposed cover plate configurations}

In the first step, two base configurations are examined. Single cover plate configuration (Model A) is shown in Fig. 1. This domain comprises cover and absorber plate, air trapped between them and channel with working fluid. Configuration with honeycomb cover plate (Model B) is shown in Fig. 2. This design includes cover plate with channels inside it (honeycomb cover plate), absorber plate, air in the enclosure between cover and absorber plate, and channels with working fluid. Such design is considered because the air trapped inside channels acts like insulator thus increasing overall collector top resistance to heat loss. This could potentially result in an increased thermal efficiency. On the other hand, increased overall collector top resistance top heat loss could also increase stagnation temperature inside the collector. For these two designs, both the thermal efficiency and stagnation temperature are evaluated. In the second step, different passive cooling methods are investigated. As this type of polymer collector is designed to work in a drain-back mode, during the stagnation regime working fluid (e.g. water) inside channels in absorber plate will be drained out and replaced by air. In that case, collector can be equipped with additional channel that will connect absorber and cover plate channels. This would allow air flow inside collector only in stagnation regime which can potentially result in reduced stagnation temperature (shown in Fig. 3). Three different channel widths are analysed: $4.25 \mathrm{~mm}, 10 \mathrm{~mm}$, and $20 \mathrm{~mm}$ (Model B1-B3). It is important to note that only a concept of overheating protection method is analysed in this paper. Second passive cooling method that use additional channel below the absorber plate is shown in Fig. 4 and Fig. 5. Since the absorber plate is the most heavily loaded part of the collector, such method would allow flow of the ambient air directly below the absorber plate. This method is applied in both proposed cover plate configurations (Model A1 and Model B4). For Model A and Model B both thermal efficiency and temperature field are evaluated by varying operating conditions such as solar irradiation and ambient temperature. On the other hand, for Model B1-B4 and A1 only temperature and velocity field are obtained. It should be noted that for now, the proposed passive cooling methods are only virtually prototyped and numerical simulations are performed to prove validity of the used methods.

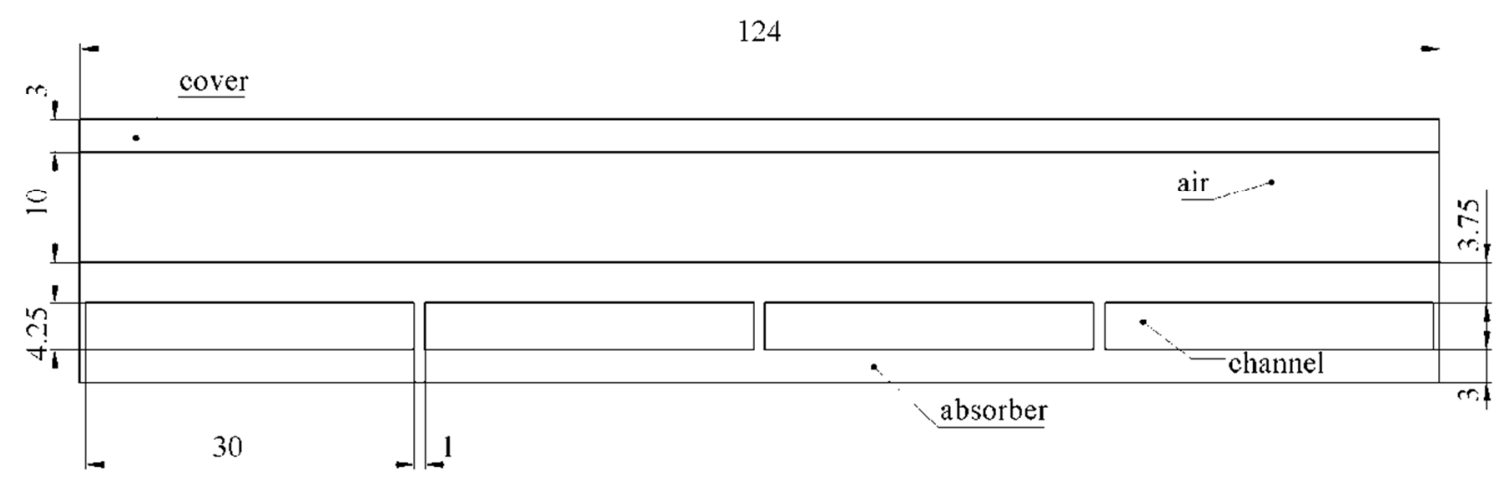

Fig. 1 Model A - Single cover plate 


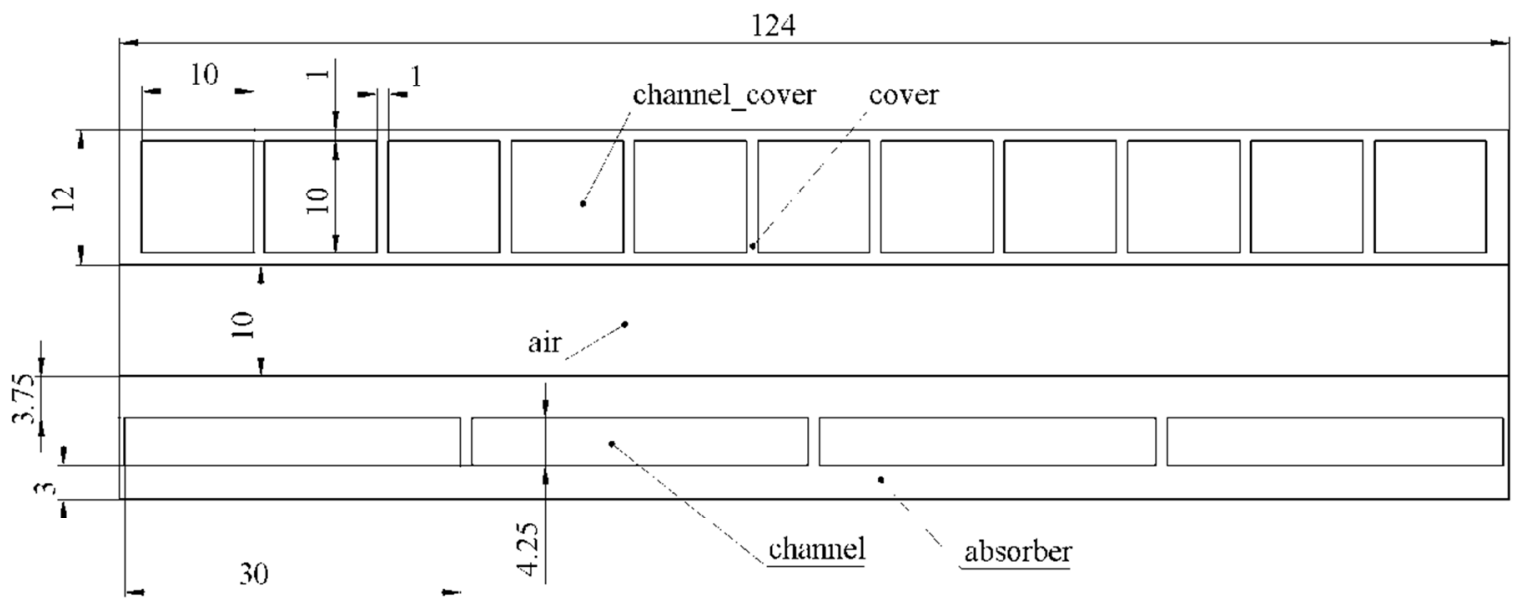

Fig. 2 Model B - Honeycomb cover plate configuration

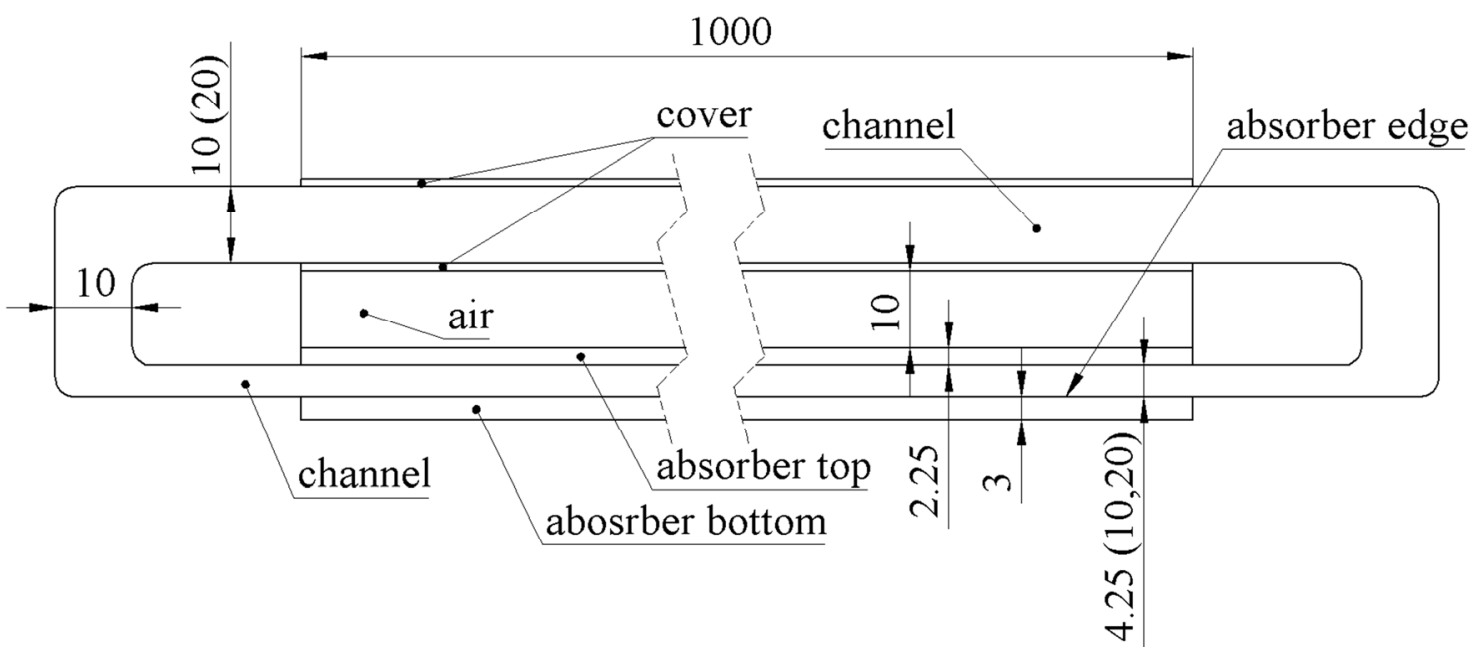

Fig. 3 Model B1 - Honeycomb cover plate configuration with enabled flow between cover and absorber

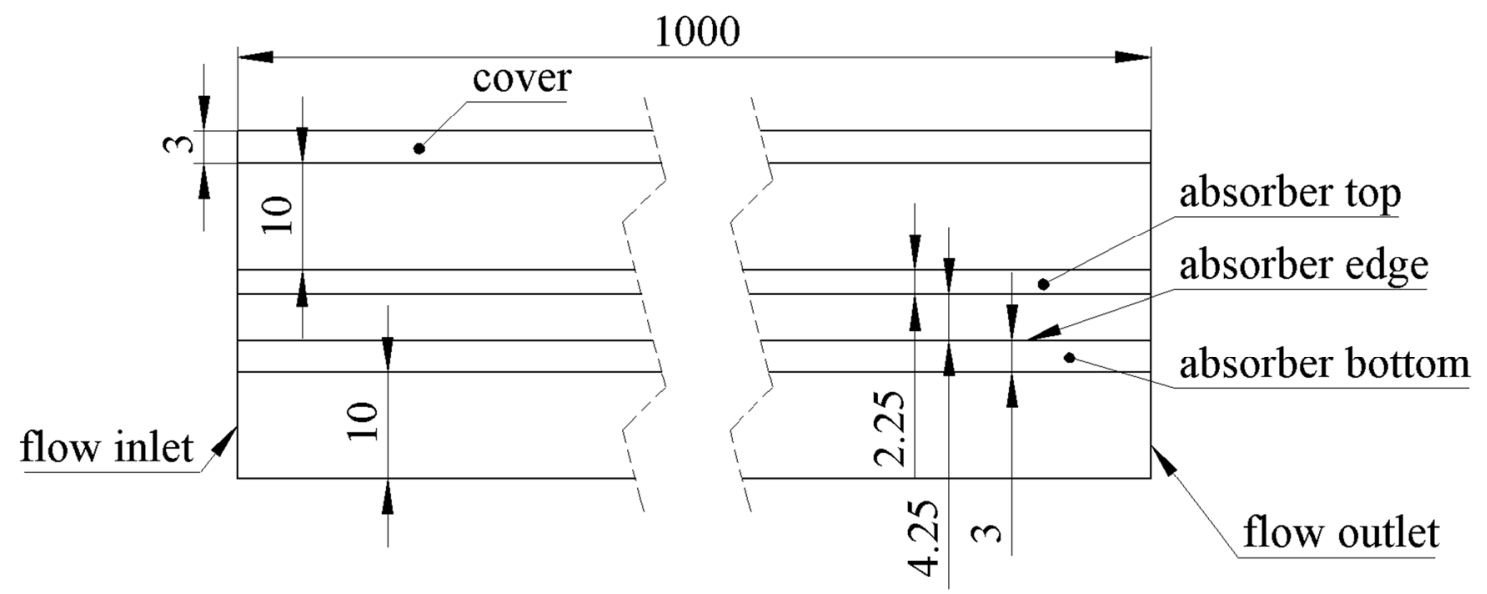

Fig. 4 Single cover plate configuration with additional channel below the absorber plate 


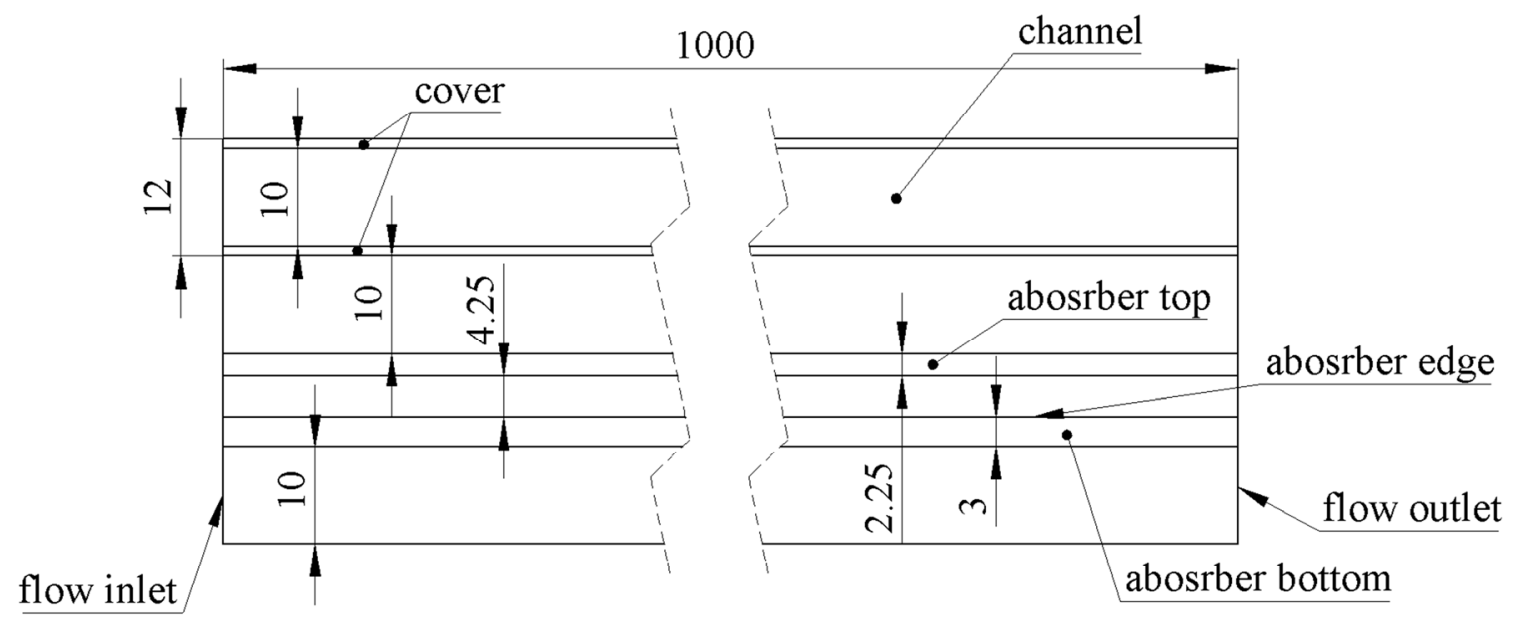

Fig. 5 Honeycomb cover plate configuration with additional channel below the absorber plate

\subsection{Boundary conditions}

As previously stated, solar radiation is modelled with the ray tracing software and radiative heat transfer due to longwave radiation is taken into the account with DO radiation model. Thermal performances are assessed for different operating conditions. For Model AA and Model B, both thermal efficiency and temperature field are obtained, while for Model B1B4 and A1 only temperature field is evaluated. Boundary conditions applied to each computational domain are listed in the tables below.

Table 1 Boundary conditions for Model A and Model B

\begin{tabular}{ccc}
\hline \multicolumn{3}{c}{ Model A and Model B (both operating, and stagnation regime are considered) } \\
\hline & Operating regime & Stagnation regime \\
\hline $\mathrm{G}_{\text {sun }},\left[\mathrm{W} / \mathrm{m}^{2}\right]$ & 1000 & 1000 \\
$\mathrm{~T}_{\text {ambb }},\left[{ }^{\circ} \mathrm{C}\right]$ & 35 & 35 \\
$\alpha_{\text {wind, }}\left[\mathrm{W} / \mathrm{m}^{2} \mathrm{~K}\right]$ & 10 & 5 \\
& \multicolumn{2}{c}{$27 / 397.14$} \\
& $35 / 404.92$ \\
$\mathrm{~T}_{\text {water }} / \alpha_{\text {water, }}$ & \multicolumn{3}{c}{$31 / 417.87$} \\
{$\left[{ }^{\circ} \mathrm{C} / \mathrm{W} / \mathrm{m}^{2} \mathrm{~K}\right]$} & $67 / 427.33$ \\
& $91 / 435.13$ \\
\hline
\end{tabular}

Table 2 Boundary conditions for Model B1-B4 and A1

\begin{tabular}{cc}
\hline \multicolumn{2}{c}{ Model B1-B4, A1 } \\
\hline \multicolumn{2}{c}{ (only stagnation regime is considered) } \\
\hline $\mathrm{G}_{\text {sun, }}\left[\mathrm{W} / \mathrm{m}^{2}\right]$ & 1000 \\
$\mathrm{~T}_{\text {amb }},\left[{ }^{\circ} \mathrm{C}\right]$ & 35 \\
$\alpha_{\text {wind, }}\left[\mathrm{W} / \mathrm{m}^{2} \mathrm{~K}\right]$ & 5 \\
\hline
\end{tabular}




\section{Results and discussion}

\subsection{Results obtained for Model A and Model B}

Computed thermal efficiency for Model A and Model B is shown in Fig. 6. At lower water temperature values, Model A tends to have higher thermal efficiency than Model B. As mentioned before, honeycomb cover plate behaves like insulator due to air trapped inside channels, consequently increasing overall collector top heat loss. Hence, at higher water temperature values (higher reduced temperature difference), Model B is more efficient than Model A. This phenomenon can also be observed in Fig. 7. Furthermore, using cover plate with channels puts more stress on the cover plate in a normal operating regime. As mentioned earlier, such design increases temperature of the whole collector during the stagnation regime. Temperature filed in stagnation regime is shown in Fig. 8. As it can be observed, maximum temperatures occur on the absorber plate in both models. In Model $\mathrm{B}\left(\sim 140^{\circ} \mathrm{C}\right)$ maximum temperature is about $\sim 20^{\circ} \mathrm{C}$ higher than in Model $\mathrm{A}\left(\sim 120^{\circ} \mathrm{C}\right)$. This presents a relatively high increase in stagnation temperature and further analysis based on calculation of thermal efficiency during a period of whole year is needed. Furthermore, relatively high temperatures during stagnation regime are observed and overheating protection is necessary in order to ensure proper operation of a polymer solar collector during a normal lifespan.

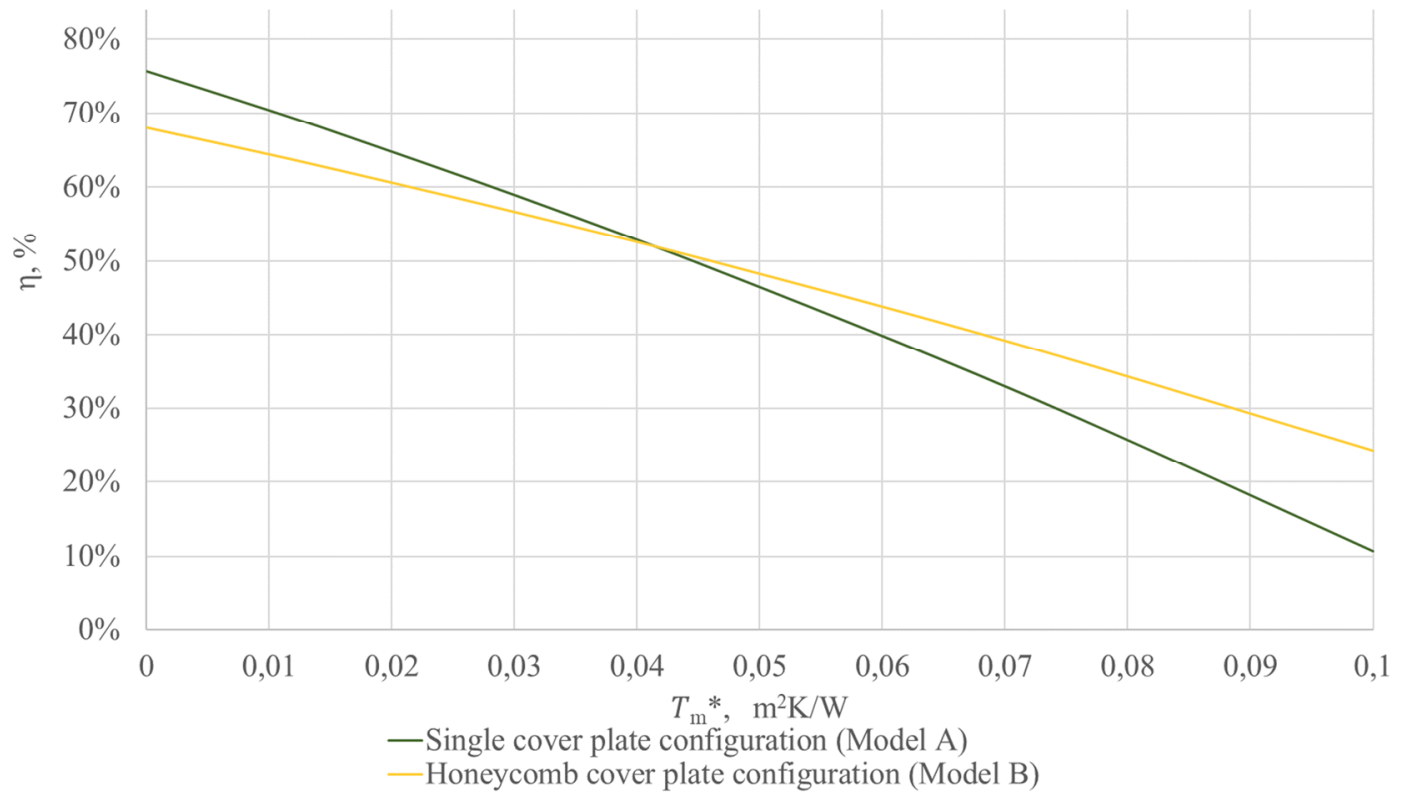

Fig. 6 Computed efficiency for Model A and Model B 
P. Filipović, D. Dović,

I. Horvat, B. Ranilović
Numerical Investigation of Cover Plate Configurations Effect on Thermal Characteristics of a Polymer Solar Collector
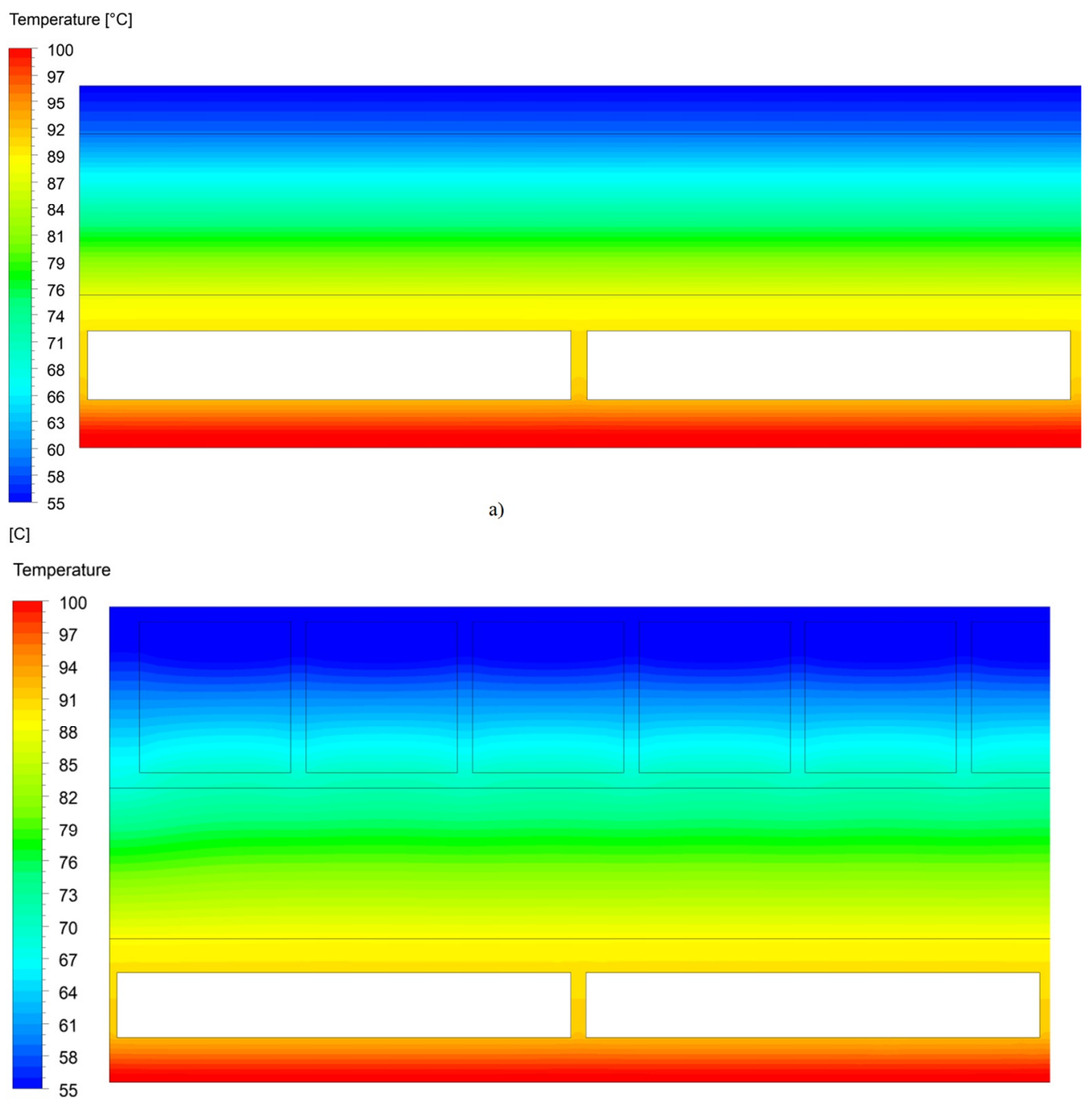

[C]

b)

Fig. 7 Temperature field during operating regime; $\mathrm{G}=1000 \mathrm{~W} / \mathrm{m}^{2} ; \mathrm{T}_{\mathrm{amb}}=35^{\circ} \mathrm{C} ; \mathrm{T}_{\text {water }}=91^{\circ} \mathrm{C}$;

a) Model A, b) Model B 

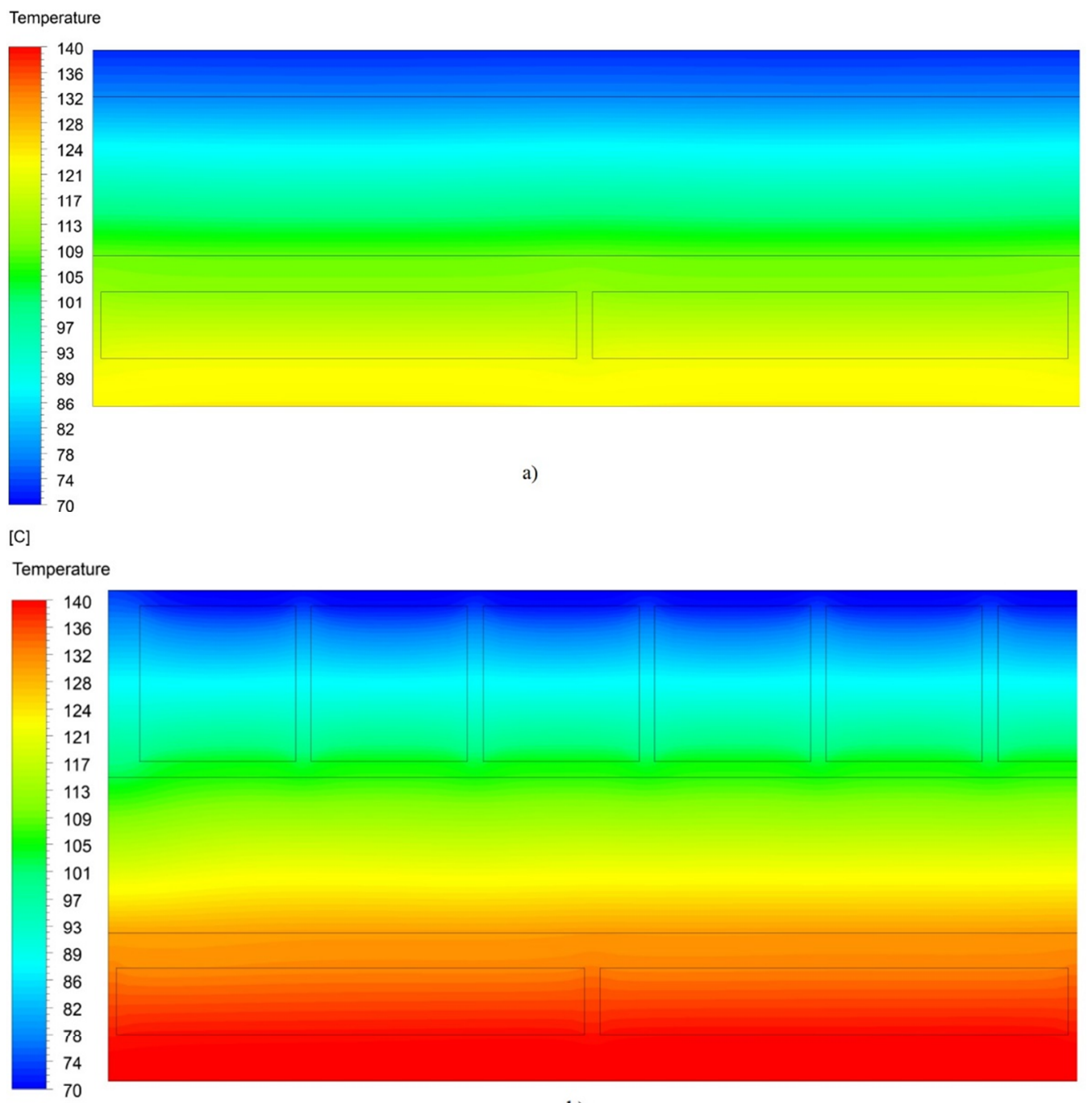

[C]

b)

Fig. 8 Temperature field for in stagnation regime; $\mathrm{G}=1000 \mathrm{~W} / \mathrm{m}^{2} ; \mathrm{T}_{\mathrm{amb}}=35^{\circ} \mathrm{C}$;

a) Model A, b) Model B

\subsection{Analysis of passive cooling methods}

In the section before, thermal efficiency and stagnation temperature of two different polymers solar collector designs are evaluated. It is observed that in stagnation regime, temperatures inside collector rise far above $100^{\circ} \mathrm{C}\left(\sim 120^{\circ} \mathrm{C}\right.$ in Model A and $\sim 140^{\circ} \mathrm{C}$ in Model $\mathrm{B})$, which is considered as a temperature at which degradation and deformation of low-cost polymeric materials occurs. Such high temperature values can be maintained only for a short period of time, while longer exposure results in malfunction of polymer solar collector. Thus, overheating protection for this type of polymer solar collector is necessary. A passive overheating protection method based on natural convection is proposed in this paper. As this type of collector is intended to operate in drain back mode, during the stagnation period channels beneath the absorber plate contain air instead of working fluid (e.g. water). Connection of absorber and cover plate channels allows the air flow inside collector. Results of numerical analysis for 3 different channel widths are presented below (Table 3). It can be observed that for all three channel widths average temperature of the absorber plate is lower in case with airflow compared to case without airflow. On the other hand, it is noted that maximum absorber temperature is increased when the airflow is introduced for Model B1 and 
P. Filipović, D. Dović,

I. Horvat, B. Ranilović
Numerical Investigation of Cover Plate Configurations Effect on Thermal Characteristics of a Polymer Solar Collector

B2, while in Model B3 the maximum obtained temperature is also lower in case with air flow inside collector.

Table 3 Results obtained for Model B1-B3

\begin{tabular}{|c|c|c|c|c|}
\hline & \multicolumn{2}{|c|}{ With air flow } & \multicolumn{2}{|c|}{ Without air flow } \\
\hline & $\mathrm{T}_{\text {avg }}$ & $\mathrm{T}_{\max }$ & $T_{\text {avg }}$ & $\mathrm{T}_{\max }$ \\
\hline \multicolumn{5}{|c|}{ Model B1 $(4,25 \mathrm{~mm})$} \\
\hline absorber top & 122.07 & 137.11 & 125.23 & 130.82 \\
\hline absorber bottom & 131.57 & 145.15 & 135.17 & 140.35 \\
\hline \multicolumn{5}{|c|}{ Model B2 $(10 \mathrm{~mm})$} \\
\hline absorber top & 112.06 & 141.22 & 124.70 & 129.92 \\
\hline absorber bottom & 120.79 & 148.47 & 136.77 & 141.42 \\
\hline \multicolumn{5}{|c|}{ Model B3 $(20 \mathrm{~mm})$} \\
\hline absorber top & 107.74 & 125.52 & 125.67 & 136.47 \\
\hline absorber bottom & 115.47 & 134.02 & 138.37 & 148.17 \\
\hline
\end{tabular}

In Fig. 9 heat flux and temperature values on "absorber edge" for Model B1 are shown. Heat transfer rate is higher in the first part of the collector (entry of cooled air), resulting in the decrease of absorber temperature. Heat flux and temperature are equalized in the middle part of the collector. At the end of the collector, temperature of the absorber plate is higher in the case where there is airflow inside collector. Temperature and velocity field for Model B3 are shown in the Fig. 10 and Fig. 11.

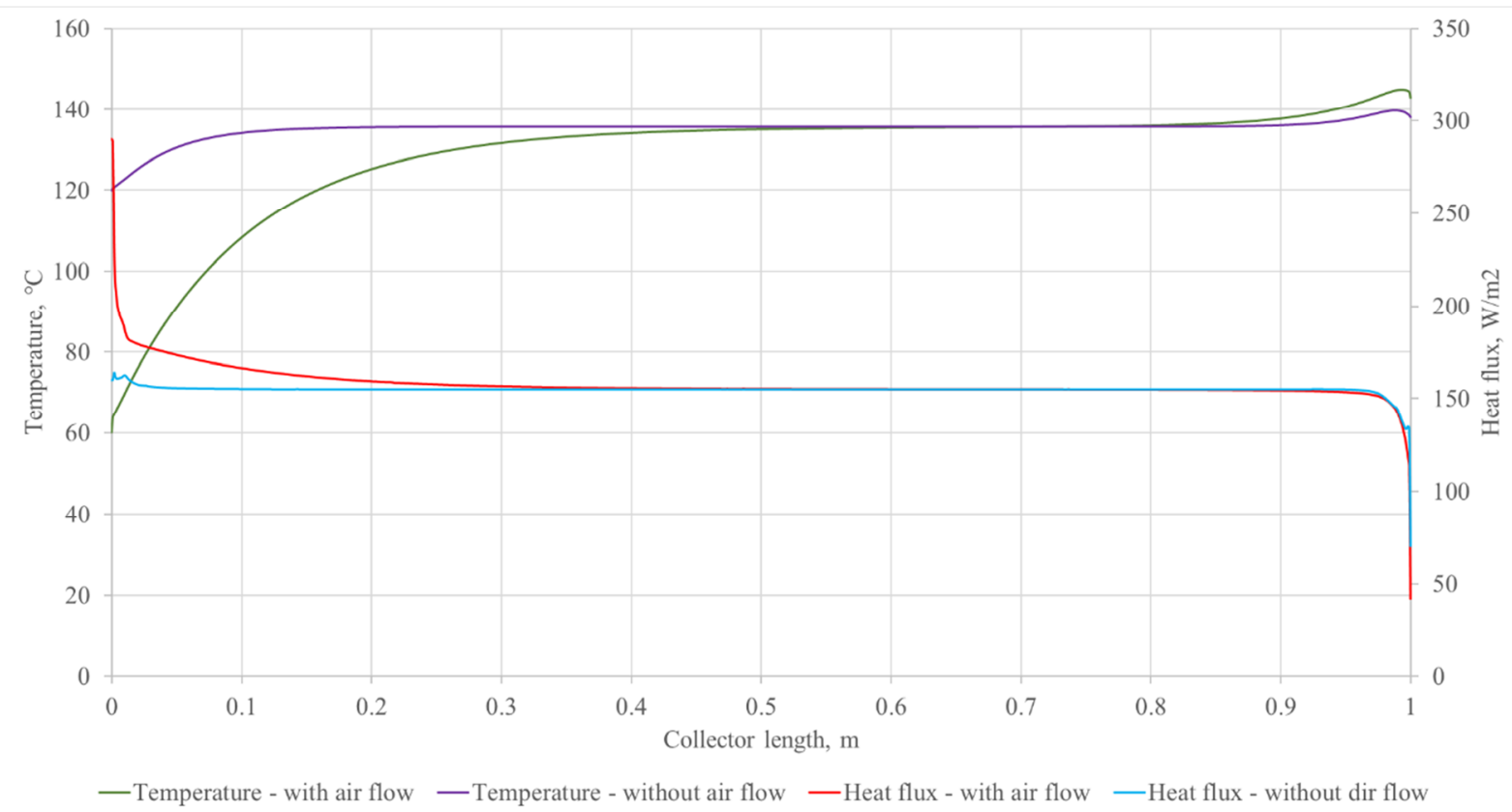

Fig. 9 Heat flux and temperature on "absorber edge"; Model B1 


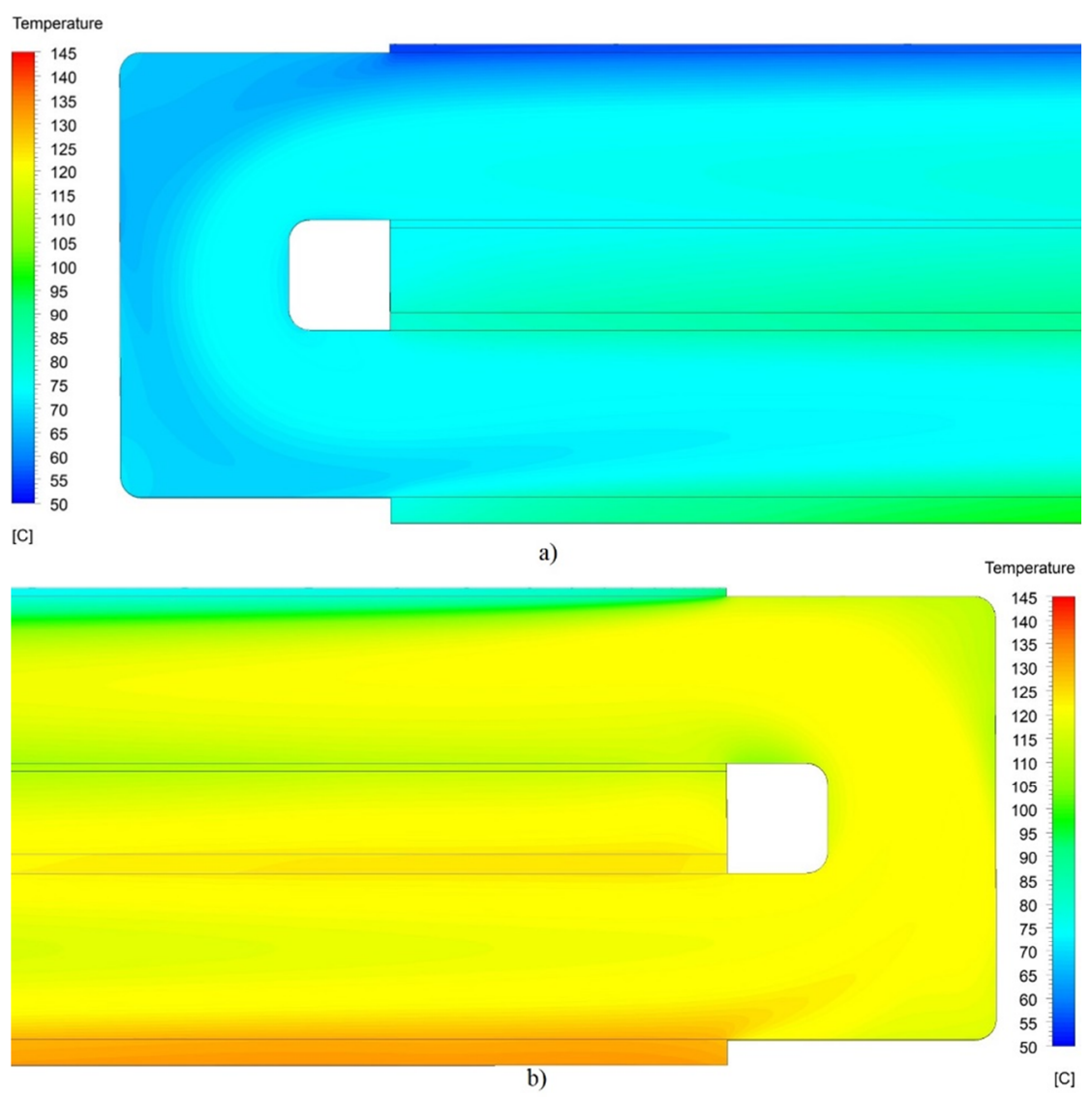

Fig. 10 Temperature field for Model B3; a) inflow of cool air, b) outflow of hot air

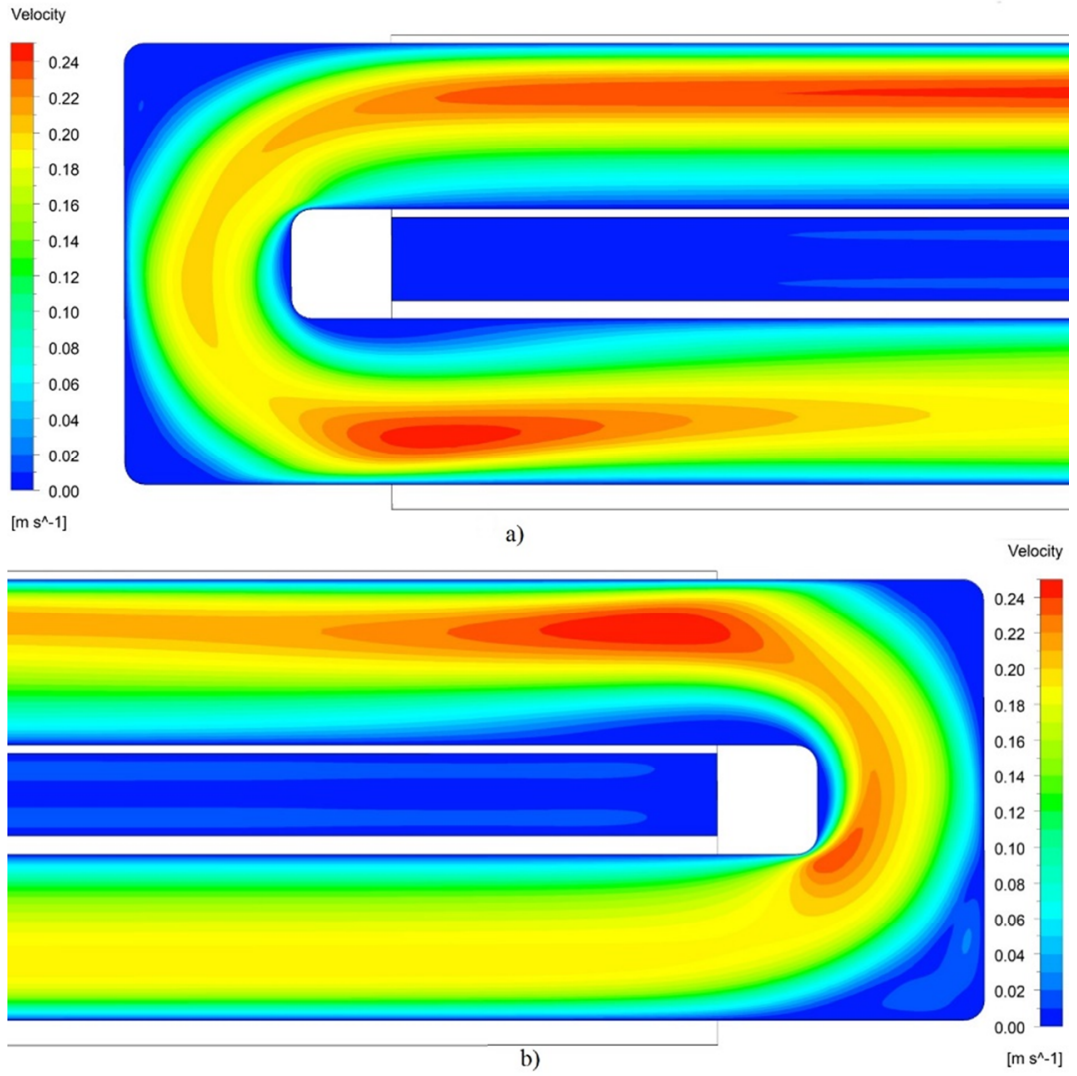

Fig. 11 Velocity for Model B3; a) inflow of cool air, b) outflow of hot air 
Second passive cooling method use additional channel below the absorber plate which would allow flow of the ambient air directly under the absorber plate. This method is applied in both base models, single cover plate and honeycomb cover plate case. In Fig. 12 temperature values on "absorber edge" for Model A1 and B4 are shown. It can be observed that in the both cases the absorber was cooled down below threshold value of $100^{\circ} \mathrm{C}\left(\sim 92^{\circ} \mathrm{C}\right.$ in Model A1 and $\sim 96^{\circ} \mathrm{C}$ in Model B4). It is also interesting to notice relatively high temperature gradient $\left(\sim 50^{\circ} \mathrm{C} / \mathrm{m}\right.$ of collector length) that occurs on the absorber plate. This can potentially result in high temperature loads and permanent deformation or expansion of collector. This problem should be investigated in the future works.

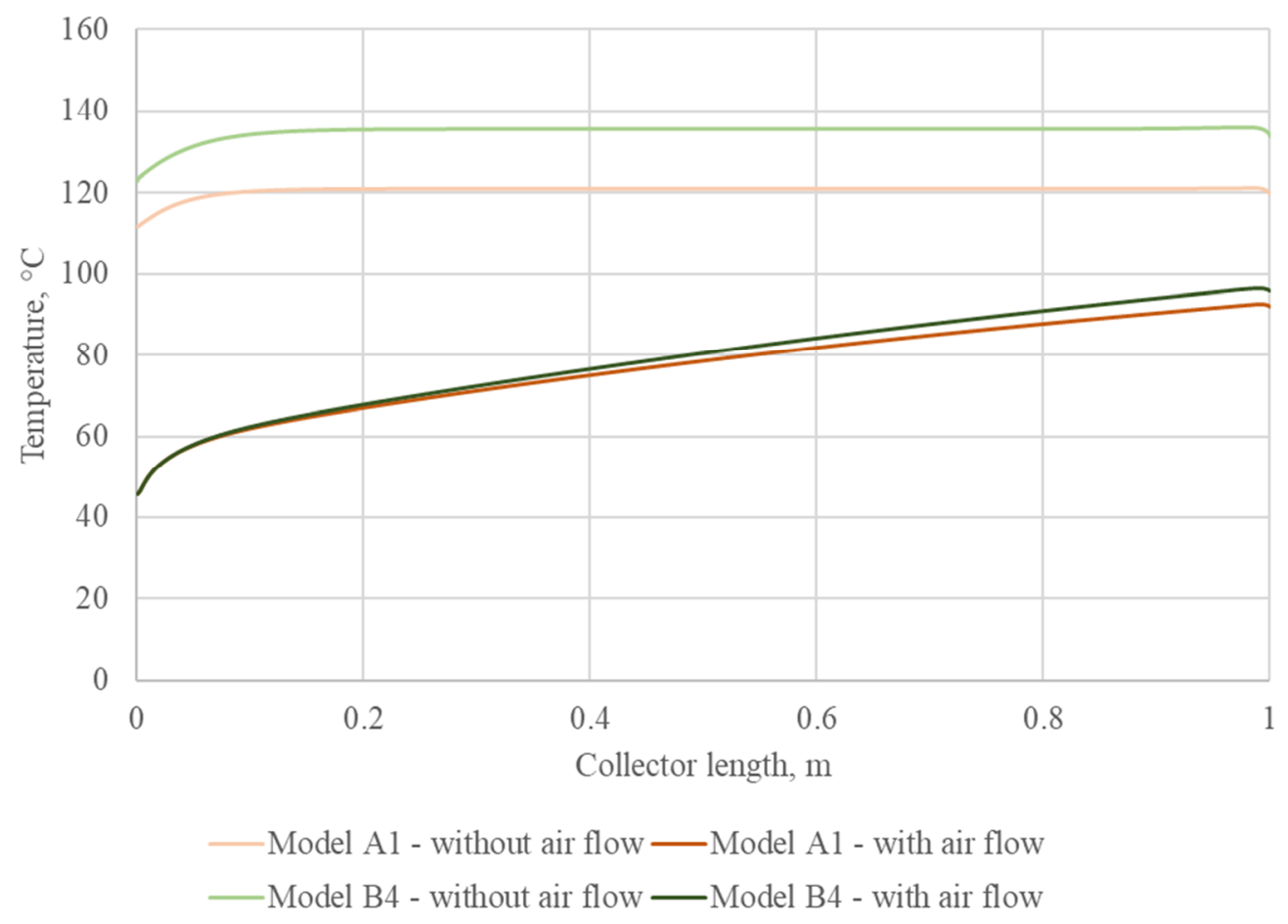

Fig. 12 Temperature on "absorber edge"; Model A1 and B4

\section{CONCLUSION}

In this paper, a part of work done in process of development of a polymer solar collector is presented. Work covers numerical analysis that investigates the influence of different cover configurations on thermal performances of such collector. Firstly, configuration with single cover plate (Model A) and honeycomb cover plate (Model B) were analysed. Thermal efficiency and temperature field are evaluated, and it is shown that Model A is more efficient in case of the lower values of reduced temperature than Model B. Air trapped inside channels in Model B behaves like insulator, increasing overall collector top resistance to heat loss as reduced temperature is increased. This result in higher efficiency of Model B design compared to configuration shown in Model A. Stagnation temperature for both designs rises far above $100^{\circ} \mathrm{C}$, which is considered as a temperature at which degradation and deformation of low-cost polymeric materials occur. Thus, overheating protection is necessary to ensure proper operation of polymer solar collector during a normal lifespan. To assess this problem passive overheating protection methods based on natural convection are proposed in this work. Since this type of a polymer collector is designed to work in a drain back system during the stagnation regime, channels inside absorber plate contain air instead of working fluid (e.g. water). This enables connection of absorber and cover plate channels to ensure air flow through the hottest parts of the collector, which should lead to temperature reduction. Three 
designs, with different channel width $(4.25,10$ and $20 \mathrm{~mm})$, were considered. Average temperature of absorber plate is reduced in all cases when airflow through collector is introduced. On the other hand, maximum temperature of the absorber plate is higher in Model B1 and B2 in case with the airflow compared to case without the airflow, whereas in Model B3 maximum temperature is also reduced when air flow is introduced. It can be concluded that only one of the analysed configurations (configuration with channel width of $20 \mathrm{~mm}$ ) would potentially result in the decrease od absorber temperature, but obtained temperatures are still above threshold value of $100^{\circ} \mathrm{C}$ and further investigation is needed.

Second method is also based on natural convection and uses additional channel below the absorber plate. This enables direct flow of ambient air below the absorber plate which leads to greater temperature reduction for both proposed configurations (below threshold value of $\left.100^{\circ} \mathrm{C}\right)$. It is also interesting to observe high temperature gradient $\left(\sim 50^{\circ} \mathrm{C} / \mathrm{m}\right.$ of collector length) which can also potentially lead to deformation of polymer solar collector and it is proposed that this method is also further investigated.

This analysis showed that numerical simulations can be useful tool in the process of designing a new type of polymer solar collector. Thermal performances of a polymer solar collector can be assessed for various operating (solar irradiance, ambient temperature etc.) and structural parameters (channels width) in order to find the most suitable design. Proposed overheating protection is only virtually prototyped and it needs to be further investigated to ensure its functionality and operability. Further steps in this research are focused on finding the most suitable overheating protection, which will enable production of the functional lowcost polymer solar collector. Based on findings, a prototype will be constructed and subjected to extensive experimental testing.

\section{REFERENCES}

[1] Islam MR, Sumathy K, Ullah S. Solar water heating systems and their market trends. Renew Sustain Energy Rev 2013;17:1-25. https://doi.org/10.1016/j.rser.2012.09.011.

[2] Alghoul MA, Sulaiman MY, Azmi BZ, Wahab MA. Review of materials for solar thermal collectors. Anti-Corrosion Methods Mater 2005;52:199-206. https://doi.org/10.1108/00035590510603210.

[3] Kahlen S, Wallner GM, Lang RW. Aging behavior of polymeric solar absorber materials - Part 1 : Engineering plastics. Sol Energy 2010;84:1567-76. https://doi.org/10.1016/j.solener.2010.03.021.

[4] Kahlen S, Wallner GM, Lang RW. Aging behavior of polymeric solar absorber materials - Part 2 : Commodity plastics. Sol Energy 2010;84:1577-86. https://doi.org/10.1016/j.solener.2010.04.007.

[5] Chen G, Doroshenko A, Koltun P, Shestopalov K. Comparative field experimental investigations of different flat plate solar collectors. Sol Energy 2015;115:577-88. https://doi.org/10.1016/j.solener.2015.03.021.

[6] Cerón JF, Pérez-García J, Solano JP, García A, Herrero-Martín R. A coupled numerical model for tubeon-sheet flat-plate solar liquid collectors. Analysis and validation of the heat transfer mechanisms. Appl Energy 2015;140:275-87. https://doi.org/10.1016/j.apenergy.2014.11.069

[7] Reichl C, Kramer K, Thoma C, Benovsky P, Lemée T. Comparison of modelled heat transfer and fluid dynamics of a flat plate solar air heating collector towards experimental data. Sol Energy 2015;120:45063. https://doi.org/10.1016/j.solener.2015.07.011

[8] Álvarez A, Tarrío-Saavedra J, Zaragoza S, López-Beceiro J, Artiaga R, Naya S, et al. Numerical and experimental study of a corrugated thermal collector. Case Stud Therm Eng 2016;8:41-50. https://doi.org/10.1016/j.csite.2016.03.007.

[9] Missirlis D, Martinopoulos G, Tsilingiridis G, Yakinthos K, Kyriakis N. Investigation of the heat transfer behaviour of a polymer solar collector for different manifold configurations. Renew Energy 2014;68:71523. https://doi.org/10.1016/j.renene.2014.03.008.

[10] Martinopoulos G, Missirlis D, Tsilingiridis G, Yakinthos K, Kyriakis N. CFD modeling of a polymer solar collector. Renew Energy 2010;35:1499-508. https://doi.org/10.1016/j.renene.2010.01.004.

[11] Mintsa Do Ango AC, Medale M, Abid C. Optimization of the design of a polymer flat plate solar collector. Sol Energy 2013;87:64-75. https://doi.org/10.1016/j.solener.2012.10.006. 
[12] Harrison S, Cruickshank CA. A review of strategies for the control of high temperature stagnation in solar collectors and systems. Energy Procedia 2012;30:793-804. https://doi.org/10.1016/j.egypro.2012.11.090.

[13] Hussain S, Harrison SJ. Experimental and numerical investigations of passive air cooling of a residential flat-plate solar collector under stagnation conditions. Sol Energy 2015;122:1023-36. https://doi.org/10.1016/j.solener.2015.10.029.

[14] Grubišić-Čabo F, Nižetić S, Marco TG. PHOTOVOLTAIC PANELS : A REVIEW OF THE COOLING. Trans FAMENA 2016;40:63-74.

[15] Nowzari R. NUMERICAL ANALYSIS OF A PHOTOVOLTAIC MODULE. Trans FAMENA 2019;43:19-30.

[16] Slaman M, Griessen R. Solar collector overheating protection. Sol Energy 2009;83:982-7. https://doi.org/10.1016/j.solener.2009.01.001.

[17] Resch-Fauster K, Weber A, Holper S, Grobbauer M. Thermotropic overheating protection for façadeintegrated solar thermal collectors. Sol Energy Mater Sol Cells 2017;170:39-47. https://doi.org/10.1016/j.solmat.2017.05.060.

[18] Gladen AC, Davidson JH, Mantell SC. The Effect of a Thermotropic Material on the Optical Efficiency and Stagnation Temperature of a Polymer Flat Plate Solar Collector. J Sol Energy Eng 2014;137:021003. https://doi.org/10.1115/1.4028366.

[19] Filipović P, Dović D, Ranilović B, Horvat I. Numerical and experimental approach for evaluation of thermal performances of a polymer solar collector. Renew Sustain Energy Rev 2019;112:127-39. https://doi.org/10.1016/j.rser.2019.05.023

$\begin{array}{ll}\text { Submitted: } & 10.10 .2019 \\ \text { Accepted: } & 03.02 .2020\end{array}$
Petar Filipović*

Damir Dović

Ivan Horvat

Borjan Ranilović

Faculty of Mechanical Engineering and

Naval Architecture

petar.filipovic@fsb.hr 